\section{RNA Polymerase II: Reading in Loops to get Different Tails}

\section{Abstract}

The DNA-loops are necessary to recycle the RNA polymerase for the multiple transcription rounds of a gene. The nascent transcript needs to be $3^{\prime}$-end processed: cleaved in a specific position and added a 3 '-end poly-(A)-tail to become an mRNA. Under regulated conditions, genes undergo 3 '-end RNA processing at different positions. This is called alternative polyadenylation (APA) and, as a consequence, mRNA molecules could have different stabilities and regulated fates. The formation of alternative DNA loops is a key factor in order to get the APA.

Keywords: RNA Polymerase; Transcription; Alternative polyadenylation; DNA loops

Received: March 28, 2016; Accepted: April 23, 2016; Published: April 28, 2016

\author{
MA. Freire-Picos \\ Department of Cell Biology and Molecular \\ Biology, Faculty of Sciences, University of A \\ Coruña, Campus of A Zapateira, Fraga \\ 10, 15008 A Coruña, Spain
}

Corresponding author:

Dr. M. Angeles Freire-Picos

mafreire@udc.es

Department of Cell Biology and Molecular Biology, Faculty of Science, University of A Coruña, Campus of A Coruña, Street Fraga 10, 15008 La Coruna, Spain.

Tel: 34981167000

Fax: 34981167065

Citation: Freire-Picos MA. RNA Polymerase II: Reading in Loops to get Different Tails. Biochem Mol Biol J. 2016, 2:1.

to the enzyme during initiation, elongation or the steps related to splicing, transcriptional termination and RNA processing. While riding the loop the polymerase will undergo multiple changes in the CTD Code and, to finally be recycled back to the promoter, its CTD must be hypo-phosphorylated.

Things become more complicated by the fact that many genes are under alternative 3 '-end processing (alternative polyadenylation, APA) [11-13]. One of these genes is the yeast KICYC1 gene $[14,15]$. The regulated APA for this gene causes two transcripts with different 3 '-UTR lengths. We have recently shown in the related article of this comment that for genes with regulated APA there is alternative DNA-loops formation also. Moreover, the predominant processing region is included in the predominant loop. Changes in RNA polymerase II positioning or the CTD phosphatase Ssu72 also correlate with both, the loop and APA predominance [16]. From the data attained for a gene with APA, it is clear the dependence of RNA processing in DNA-loop formation and, as indicated in the title, the RNA polymerase has to read the different loops in order to get messages with different tails which will depend on the cellular requirements. 


\section{References}

1 Bentley DL (2014) Coupling mRNA processing with transcription in time and space. Nature Reviews Genetics 15: 163-175.

2 Hsin JP, Manley JL (2012) The RNA polymerase II CTD coordinates transcription and RNA processing. Genes Dev 26: 2119-2137.

3 O'Sullivan JM, Tan-Wong SM, Morillon A, Lee B, Coles J, et al. (2004) Gene loops juxtapose promoters and terminators in yeast. Nat Genet 36: 1014-1018.

4 Ansari A, Hampsey M (2005) A role for the CPF 3'-end processing machinery in RNAP II-dependent gene-looping. Genes \& Dev 19: 2969-2978.

5 Tan-Wong SM, Wijayatilake HD, Proudfoot NJ (2009) Gene loops function to maintain transcriptional memory through interaction with the nuclear pore complex. Genes \& Dev 23: 2610-2624.

6 Lainé JP, Singh BN, Krishnamurthy S, Hampsey M (2009) A physiological role for gene loops in yeast. Genes Dev 23: 2604-2609.

7 Buratowski S (2003) The CTD code. Nature Structural \& Molecular Biology 10: 679-680.

8 Zhang DW, Rodríguez-Molina JB, Tietjen JR, Nemec CM, Ansari AZ (2012) Emerging views on the CTD Code. Genetics Research International.

9 Bataille AR, Jeronimo C, Jacques PE, Laramee L, Fortin ME, et al.
(2012) A universal RNA polymerase II CTD cycle is orchestrated by complex interplays between kinase, phosphatase, and isomerase enzymes along genes. Mol Cell 45: 158-170.

10 Hajheidari M, Koncz C, Eick D (2013) Emerging roles for RNA polymerase II CTD in Arabidopsis. Trends Plant Sci 18: 633-643.

11 Sparks KA, Dieckmann, CL (1998) Regulation of poly(A) site choice of several yeast mRNAs. Nucl Acids Res 26: 4676-4687.

12 Gruber AR, Martin G, Keller W, Zavolan M (2014) Means to an end: mechanisms of alternative polyadenylation of messenger RNA precursors. RNA 5: 183-196.

13 Lutz CS, Moreira A (2012) Alternative mRNA polyadenylation in eukaryotes: an effective regulator of gene expression. Wiley Interdiscip Rev RNA 2: 23-31.

14 Seoane S, Lamas-Maceiras M, Rodriguez-Torres AM, Freire-Picos MA (2009) Involvement of Pta1, Pcf11 and a KICYC1 AU-rich element in alternative RNA 3'-end processing selection in yeast. FEBS Lett 583: 2843-2848.

15 Lamas-Maceiras M, Seoane S, Freire-Picos MA (2011) Alternative Polyadenylation in Yeast: 3 '-UTR elements and processing factors acting at a distance. InTech Open access 2011: 119-136.

16 Lamas-Maceiras M, Singh BN, Hampsey M, Freire-Picos MA (2016) Alternative promoter-terminator gene loops affect alternative 3 '-end processing in yeast. J Biol Chem: In press. 